\title{
Awareness of Osteosarcoma of Jaws Among Dental Students
}

\author{
Srinisha. $\mathrm{M}^{1}$, Dhanraj Ganapathy ${ }^{2}$ and Subhashree $\mathrm{R}^{3}$ \\ ${ }^{1}$ Saveetha Dental College and Hospitals Saveetha Institute of Medical \\ and Technical Sciences Saveetha University, India \\ ${ }^{2}$ Professor and Head of Department, Department of Prosthodontics, 1 Saveetha Dental College and \\ Hospitals Saveetha Institute of Medical and Technical Sciences Saveetha University, Chennai, India. \\ ${ }^{3}$ Senior Lecturer Department of Prosthodontics Saveetha Dental College and Hospitals Saveetha \\ Institute of Medical and Technical Sciences Saveetha University Chennai -77, India
}

\begin{abstract}
Osteosarcomas are rare, malignant, bone tumors defined by the presence of malignant mesenchymal cells which produce immature bone. Osteosarcomas of the jaws are rare, representing about 7\% of all the osteosarcomas and $1 \%$ of all head and neck malignancies The mandible and maxilla are almost equally involved, but in some studies mandibular tumors have better prognosis than maxillary tumors. Osteosarcoma is a disease of childhood and adolescence peaking in the second decade of life. The aim of this study is to assess and create awareness about osteosarcoma of jaws among dental students. The survey is an online based questionnaire made using survey planet and a total of 106 responses were received.The data was tabulated in excel and statistically analysed using SPSS. About 92.5\% of dental students are aware about the malignant primary tumour of bone, osteosarcoma. About 87.7\% of dental students agree that fluoride in drinking water leads to greater risk of osteosarcoma of jaws. 73.6\% of dental students are well aware of the symptoms of osteosarcoma of jaws . The awareness about osteosarcoma among dental students is high among dental students.
\end{abstract}

KEY WORDS: OSTEOSARCOMA ; DENTAL STUDENTS; MALIGNANT; SWELLING.

\section{INTRODUCTION}

Osteosarcomas are rare, malignant, bone tumors defined by the presence of malignant mesenchymal cells which produce immature bone. Osteosarcomas of the jaws are rare, representing about 7\% of all the osteosarcomas and $1 \%$ of all head and neck malignancies (August et al., 1997;

\section{ARTICLE INFORMATION}

*Corresponding Author:dhanraj@saveetha.com

Received 4th June 2020 Accepted after revision 7th August 2020

Print ISSN: 0974-6455 Online ISSN: 2321-4007 CODEN: BBRCBA

Thomson Reuters ISI Web of Science Clarivate Analytics USA and Crossref Indexed Journal

\section{Clarivate}

crossef

NAAS Journal Score 2020 (4.31) SJIF: 2020 (7.728)

A Society of Science and Nature Publication,

Bhopal India 2020. All rights reserved.

Online Contents Available at: http//www.bbrc.in/

Doi: http://dx.doi.org/10.21786/bbrc/13.7/6
Vadillo et al., 2011). The mandible and maxilla are almost equally involved, but in some studies mandibular tumors have better prognosis than maxillary tumors (August et al., 1997). Osteosarcoma is a disease of childhood and adolescence peaking in the second decade of life. Despite many efforts, the etiology of osteosarcoma remains largely unknown.

Osteosarcoma of jaw is generally uncommon and despite its histopathologic similarities with long bone tumour, it is biologically different (Baghaie and Motahari, 2003) .The gene associated with osteosarcoma was the $\mathrm{p} 53$ gene where the mutations in the $\mathrm{p} 53$ gene were first observed in sporadic osteosarcoma (Friend et al., 1986; Iavarone and Matthay, 1992). In most cases, this type of tumour 
pursues an aggressive course. Osteosarcoma of the jaws is slightly more common in males and occurs at a later age compared to that occurring in long bones (Khorate et al., 2010).

The most common presentation of osteosarcoma in the head and neck region is swelling (Nissanka et al., 2007) . Pain has also been reported in approximately 50\% of patients with osteosarcoma (Mark et al., 1991). CT can be helpful in visualizing extension of soft-tissues involvement and is essential for early diagnosis of osteosarcoma (Givol et al., 1998) . Marx et al. reported that the prognosis of a jaw osteosarcoma is better than that of long bones osteosarcoma. The reason could be histologically better differentiation of jaw osteosarcoma than long bone osteosarcoma . As jaw osteosarcoma occurs among older aged patients have less chance of developing metastasis (Marx and Stern, 2012) .Osteosarcoma of jaws gives rise to distant metastasis less frequently compared to osteosarcomas of the long bones (Campanacci, 1999; Guadagnolo et al., 2009).

The early lesion of osteosarcoma of the jaw usually involves the surface of the bone with attachment of the lesion to the cortex and with very minimal or no trabecular involvement. Whereas, An advanced lesion may show extensive trabecular infiltration (Bras et al., 1980; Donaldson et al., 2004) . Proper surgical excision of the primary lesion combined with postoperative radiotherapy or chemotherapy is considered as the mainstay of treatment for osteosarcoma of the jaw bone (Amaral et al., 2008).

It is very important for dental students to be aware of osteosarcoma affecting jaws in order to provide early diagnosis. Previously our department has published extensive research on various aspects of prosthetic dentistry (Anbu et al., 2019; Ariga et al., 2018; Ashok and Ganapathy, 2019; Duraisamy et al., 2019; Ganapathy et al., 2017; Gupta et al., 2018; Jain, 2017a, 2017b; Ranganathan et al., 2017; Varghese et al., 2019; World Journal of Dentistry, 2017), this vast research experience has inspired us to research about the awareness of osteosarcoma of jaws among dental students.

\section{MATERIAL AND METHODS}

The present study is an online based survey conducted among the dental students. The participants were from 1 st, $2 \mathrm{nd}$, 3rd, 4th and Intern years of BDS. Questionnaires were prepared and distributed among dental students through an online link from the survey planet. The total number of participants was 106 dental students. Participation in this study was voluntary. The questionnaire contained 15 questions. Independent variables were demographics such as year of study of participants. Dependent variables were osteosarcoma of jaw, dental students. Only the completed surveys were included for analysis. The collected results were entered in Microsoft excel. Data analysis was done using SPSS software 20.0. Statistics used for analysis was Descriptive statistics and comparison of variables were done using chi square test where $p<0.05$, statistically significant.

\section{RESULTS AND DISCUSSION}

Osteosarcoma is the most common malignant bone tumor, with mandibular and maxillary osteosarcomas accounting for only $6 \%$ of all osteosarcomas (Baumhoer et al., 2014) . Osteosarcoma of the jaw has a better prognosis than that of long bone osteosarcomas (Daffner et al., 2002; Yamamoto et al., 2011). Swelling is the most common symptom in osteosarcoma. Pain, paresthesia, and ulcerations are usually less common (Jasnau et al., 2008) .

Students from different years participated in the survey. The highest number of participants were from third years (37.74\%) (Figure 1). About 92.5\% dental students were aware of osteosarcoma whereas $7.5 \%$ dental students were still not aware of malignant primary tumours of bone , osteosarcoma (Figure 2). 89.6\% of dental students were aware that osteosarcoma of jaws constitutes 7\% of all sarcomas (Figure 3). About 74.5\% dental students were aware that radiation, rapid bone growth, genetic predisposition are all the risk factors causing osteosarcoma of jaws (Figure 4).

Figure 1: Pie chart depicting the distribution of year of study of the dental students participated in the survey. Blue colour indicates 1st year students (4.72\%). Green colour indicates 2 nd year students (19.81\%). Brown colour indicates 3 rd year students (37.74\%). Violet colour indicates 4 th year students (16.04\%). Yellow colour indicates intern students $(21.70 \%)$. The highest number of participants were from third years (37.74\%).

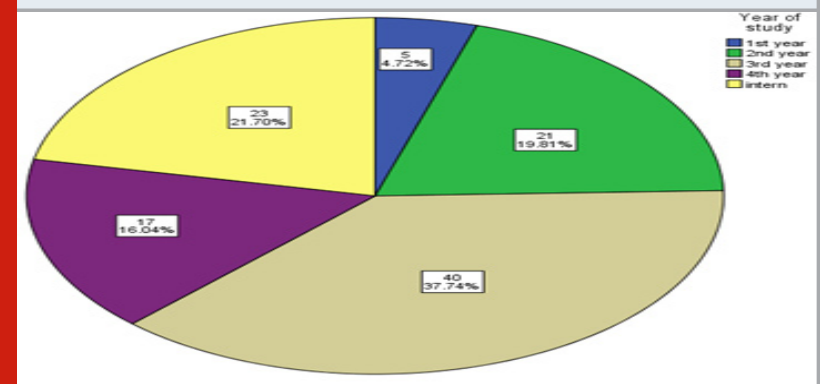

Figure 2: Pie chart depicting the awareness of osteosarcoma among the dental students participated in the survey. Blue colour indicates students who were aware of osteosarcoma (92.45\%). Green colour indicates students who were not aware of osteosarcoma (7.55\%). About 92.5\% dental students were aware of osteosarcoma .

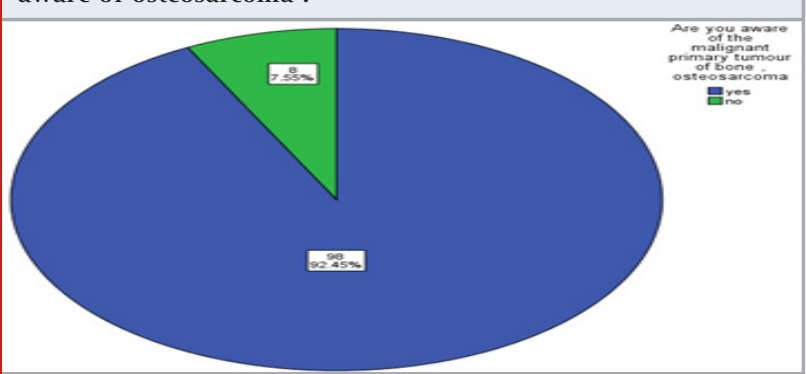


Figure 3: Pie chart depicting the awareness of students on jaw osteosarcoma which constitutes about $7 \%$ of all sarcomas among the dental students participated in the survey. Blue colour indicates students who were aware that jaw osteosarcoma represents about 7\% of all sarcoma $(89.62 \%)$. Green colour indicates students who were aware that jaw osteosarcoma represents about $7 \%$ of all sarcoma $(10.38 \%) .89 .6 \%$ of dental students were aware that osteosarcoma of jaws constitutes $7 \%$ of all sarcomas.

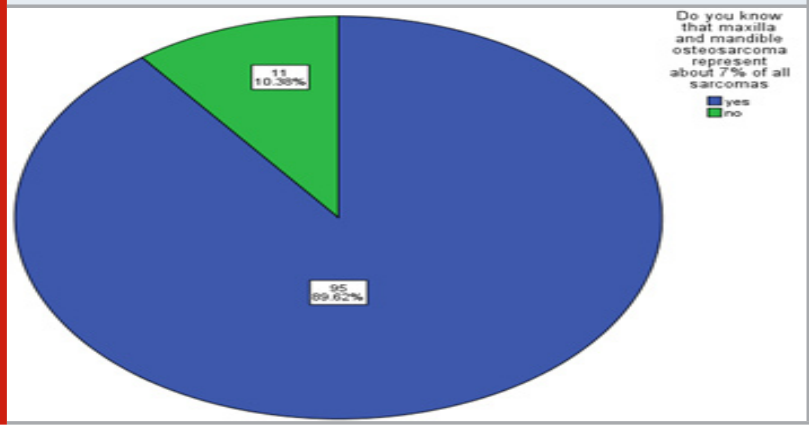

Figure 4: Pie chart depicting the risk factors causing osteosarcoma of jaws. Blue colour indicates genetic predisposition $(4.72 \%)$. Green colour indicates rapid bone growth $(7.55 \%)$. Brown colour indicates radiation $(12.26 \%)$. Violet colour indicates none of the above (0.94\%). Yellow colour indicates all of the above (74.53\%). About 74.5\% dental students were aware that radiation, rapid bone growth, genetic predisposition are all the risk factors causing osteosarcoma of jaws.

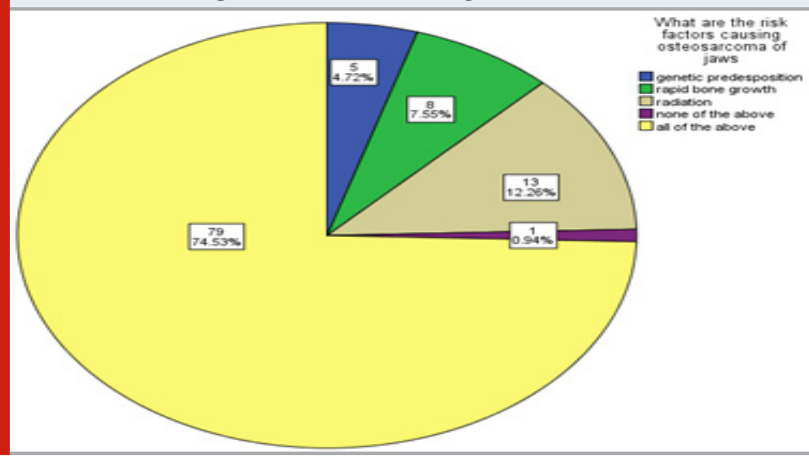

Figure 5: Pie chart depicting the gender most affected by osteosarcoma according to the participants. Blue colour indicates male (65.09\%). Green colour indicates female (24.53\%). Brown colour indicates both gender equally affected (10.38\%). About 65.1\% dental students responded that males are most affected by osteosarcoma.

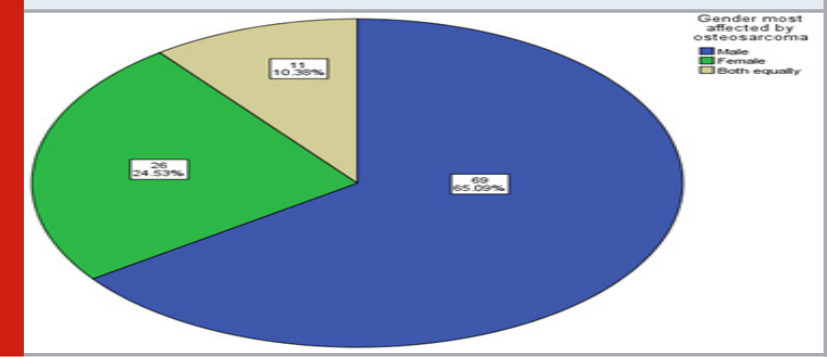

About 65.1\% dental students responded that males are most affected by osteosarcoma, 24.5\% responded that females are most affected by osteosarcoma and $10.4 \%$ responded that both genders are affected equally (Figure 5). About 78.3\% dental students were aware that occurrence of osteosarcoma of jaws are related to dental extractions (Figure 6). 79.25\% were well aware that the commonest findings of osteosarcoma of jaws was swelling (Figure 7). About 96.2\% dental students were aware that the survival rate of osteosarcoma has increased on using chemotherapy as an adjuvant to surgery (Figure 8).

Figure 6: Pie chart depicting the awareness of the dental students on extraction as a cause for osteosarcoma. Blue colour indicates students who agreed that osteosarcoma is caused by extraction (78.30\%). Green colour indicates students who did not agree that osteosarcoma is caused by extraction (21.70\%). About 78.3\% dental students were aware that occurrence of osteosarcoma of jaws are related to dental extractions.

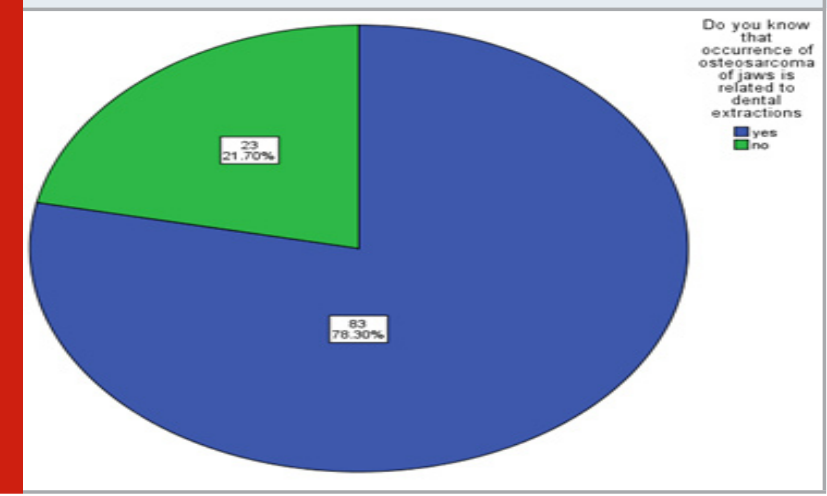

Figure 7: Pie chart depicting the awareness of the dental students on swelling as the most common clinical presentation of osteosarcoma of jaws . Blue colour indicates students who agreed that swelling is the common finding of osteosarcoma of jaws (78.25\%). Green colour indicates students who did not agree that swelling is the common finding of osteosarcoma of jaws (20.75\%). 79.25\% were well aware that the commonest findings of osteosarcoma of jaws was swelling.

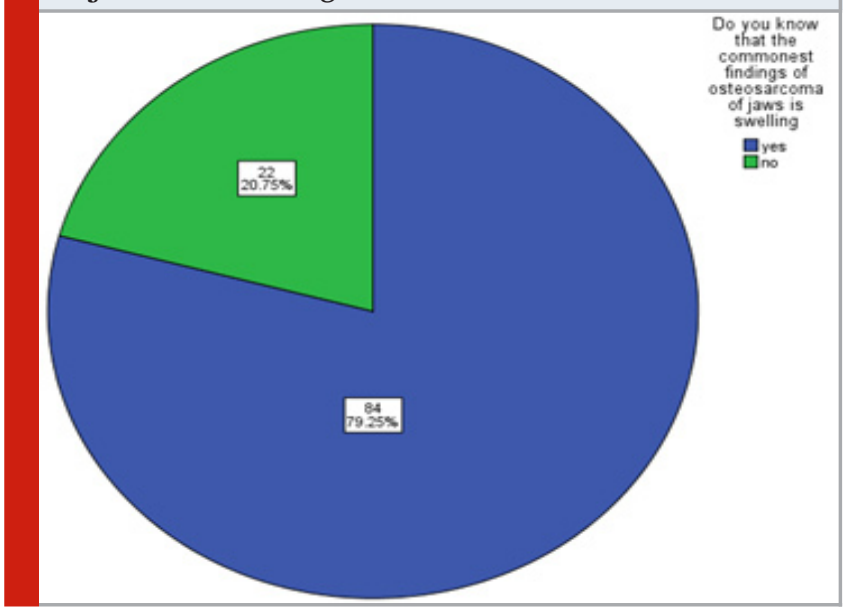


Figure 8: Pie chart depicting the awareness of the dental students on chemotherapy as an adjuvant for surgery in treatment for osteosarcoma of jaw. Blue colour indicates students who agreed that chemotherapy can be used as an adjuvant for surgery(96.23\%). Green colour indicates students who did not agree that chemotherapy can be used as an adjuvant for surgery (3.77\%). About 96.2\% dental students were aware that the survival rate of osteosarcoma has increased on using chemotherapy as an adjuvant to surgery.

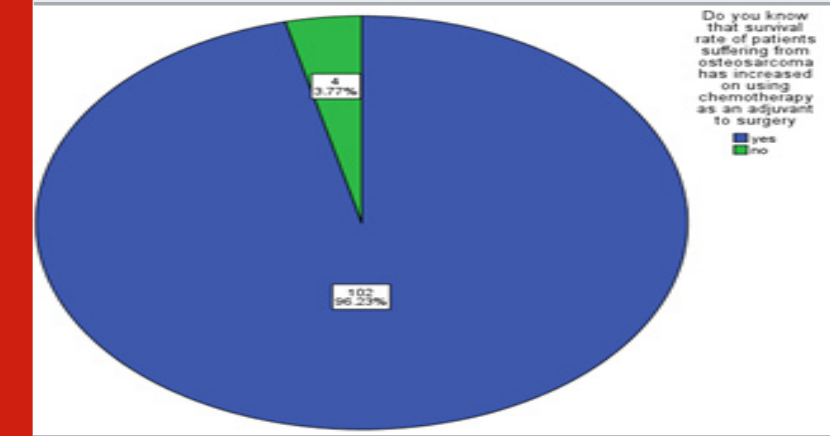

About 78.3\% students were aware that higher levels of fluoride content in drinking water can lead to osteosarcoma of jaws (Figure 9). 76.42\% were aware that peak incidence of osteosarcoma was found in the second and fourth decades (Figure 10). About 76.42\% dental students were aware that patient age, tumour grade, tumour size, response to chemotherapy all these factors affects prognosis of osteosarcoma of jaws (Figure 11). According to $73.58 \%$ of the study participants swelling, loosening of teeth are the symptoms of osteosarcoma of jaws (Figure 12).

Figure 9: Pie chart depicting the awareness of the dental students on higher levels of fluoride as a cause for osteosarcoma of jaws. Blue colour indicates students who agreed that fluoride causes osteosarcoma of jaws (78.30\%). Green colour indicates students who did not agree that fluoride causes osteosarcoma of jaws (21.70\%). About $\mathbf{7 8 . 3} \%$ students were aware that higher levels of fluoride content in drinking water can lead to osteosarcoma of jaws.

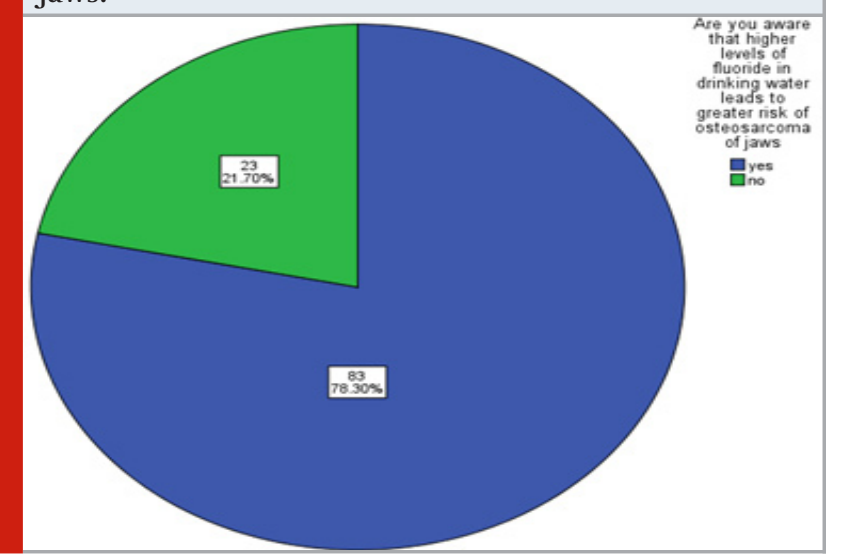

Figure 10: Pie chart depicting the awareness of the dental students on higher incidence of osteosarcoma of jaws seen in the second and fourth decades. Blue colour indicates students who agreed that higher incidence of osteosarcoma of jaws was seen in the second and fourth decades (76.42\%). Green colour indicates students who did not agree that higher incidence of osteosarcoma of jaws was seen in the second and fourth decades $(23.58 \%)$. $76.42 \%$ were aware that peak incidence of osteosarcoma was found in the second and fourth decades.

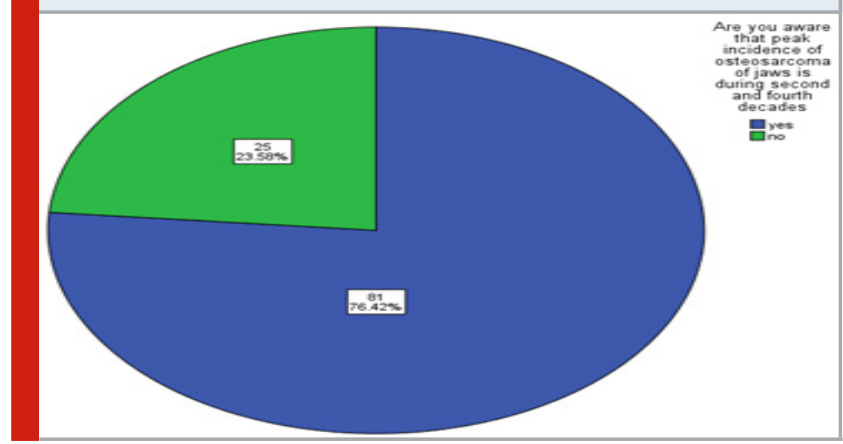

Figure 11: Pie chart depicting the factors affecting prognosis of osteosarcoma according to the participants . Blue colour indicates response to chemotherapy (2.83\%). Green colour indicates none of the above (0.94\%). Brown colour indicates patient age $(4.72 \%)$. Violet colour indicates tumour grade (3.77\%). Yellow colour indicates tumour size $(11.32 \%)$. Red colour indicates all of the above (76.42\%). About 76.42\% dental students were aware that patient age, tumour grade, tumour size, response to chemotherapy all these factors affects prognosis of osteosarcoma of jaws

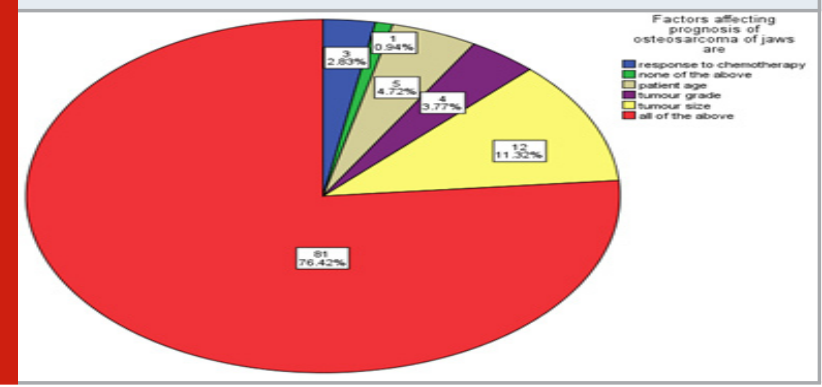

Figure 12: Pie chart depicting the symptoms of osteosarcoma of jaws according to the participants. Blue colour indicates swelling $(5.66 \%)$. Green colour indicates loosening of teeth $(7.55 \%)$. Brown colour indicates facial dysesthesia (13.21\%). Violet colour indicates all of the above (73.58\%). According to $73.58 \%$ of the study participants swelling, loosening of teeth are the symptoms of osteosarcoma of jaws.

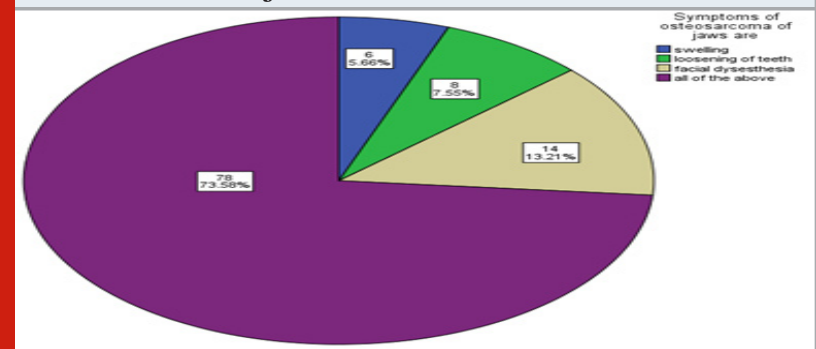


About 85.8\% dental students were aware that osteosarcoma of jaws occurs secondary to Paget's disease (Figure 13). 93.4\% dental students agreed to the fact that obtaining disease free resection margins in osteosarcoma is difficult (Figure 14). About 83\% dental students were aware of the ways to manage osteosarcoma of jaws (Figure 15).

Figure 13: Pie chart depicting the awareness of the dental students on osteosarcoma occurring secondary to Paget's disease. Blue colour indicates students who agreed that osteosarcoma occurred secondary to Paget's disease $(85.85 \%)$. Green colour indicates students who did not agree that osteosarcoma occurred secondary to Paget's disease (14.15\%). About 85.8\% dental students were aware that osteosarcoma of jaws occurs secondary to Paget's disease.

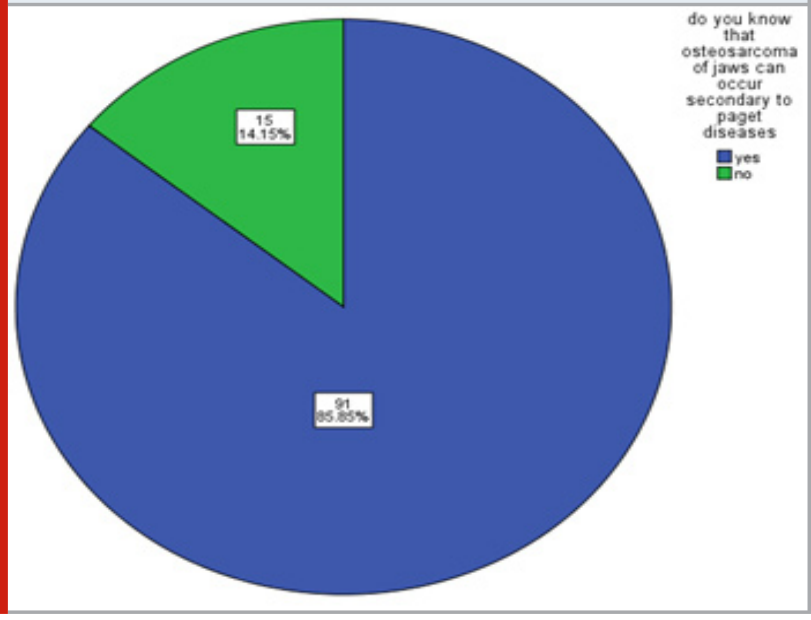

Figure 14: Pie chart depicting the awareness of dental students on obtaining disease free margin in osteosarcoma of jaws is difficult. Blue colour indicates students who agreed that obtaining disease free margin in osteosarcoma of jaws is difficult (93.40\%). Green colour indicates students who did not agree that obtaining disease free margin in osteosarcoma of jaws is difficult (6.60\%). 93.4\% dental students agreed to the fact that obtaining disease free resection margins in osteosarcoma is difficult.

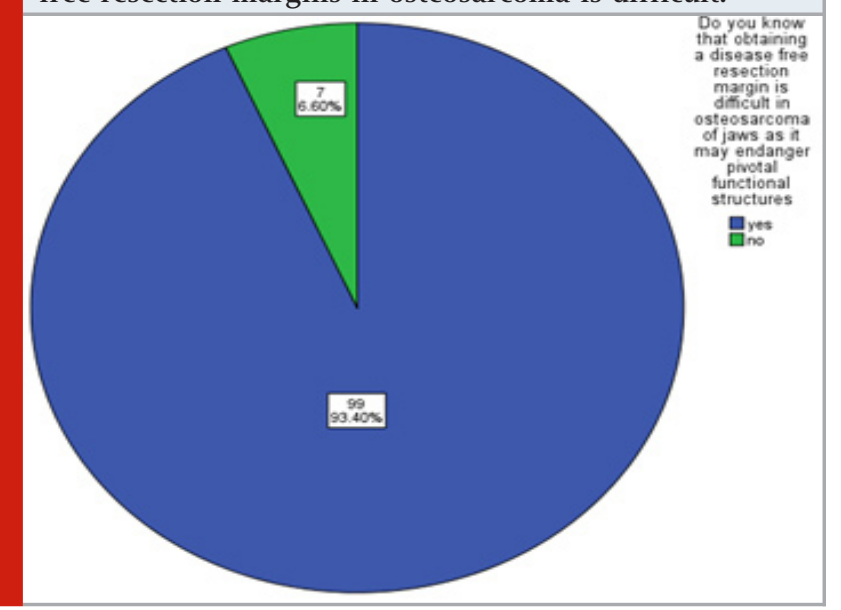

Figure 15: Pie chart depicting the awareness of dental students on ways to manage osteosarcoma of jaws. Blue colour indicates students who were aware of ways to manage osteosarcoma of jaws (83.02\%). Green colour indicates students who were not aware of ways to manage osteosarcoma of jaws (16.98\%). About 83\% dental students were aware of the ways to manage osteosarcoma of jaws.

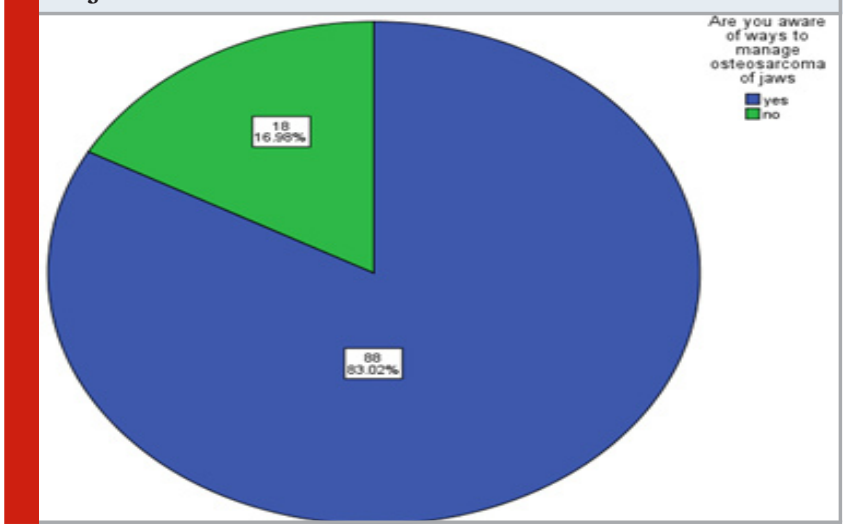

Comparison of year of study of participants and awareness of osteosarcoma of jaws was done and awareness was seen more among third years (37.14\%) compared to other years ( $\mathrm{p}=0.001$, statistically significant) (Figure 16). Comparison of year of study of participants and awareness of chemotherapy as an adjuvant for surgery as a treatment for osteosarcoma of jaws was also done and awareness was seen more among third years (37.74\%) compared to other years $(p=0.011$, statistically significant) (Figure 17). Comparison of year of study of participants and awareness of ways to manage osteosarcoma of jaws and awareness was seen more among third years (35.85\%) compared to other years ( $p=0.001$, statistically significant) (Figure 18).

Figure 16: Bar graph depicts the comparison of year of study of participants and awareness of osteosarcoma of jaws. $\mathrm{X}$ axis denotes the year of study of the participants and $\mathrm{Y}$ axis denotes the frequency distribution for the response of the question 'Are you aware of malignant primary tumour of bone, osteosarcoma'. Blue colour depicts the participants who are aware of osteosarcoma of jaws and green colour depicts the participants who are not aware of osteosarcoma of jaws . Awareness was seen more among third years $(37.74 \%)$ compared to other years. This was found to be statistically significant. (Chi square test, $\mathrm{P}=\mathbf{0 . 0 0 1}$ ).

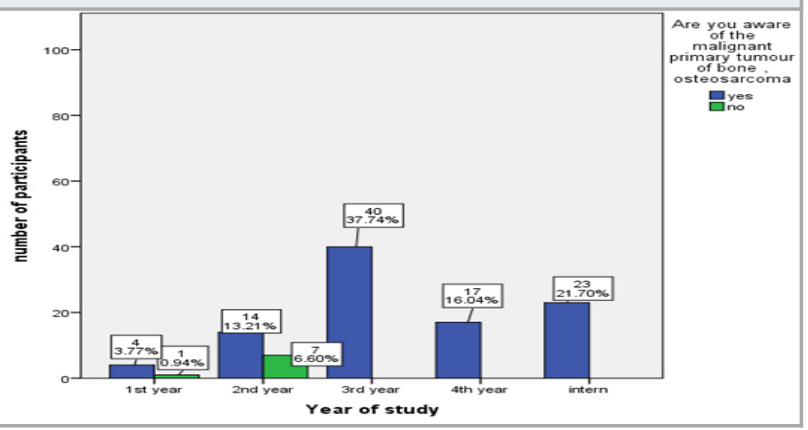


Figure 17: Bar graph depicts the comparison of year of study of participants and awareness of chemotherapy as an adjuvant for surgery as a treatment for osteosarcoma of jaws. $X$ axis denotes the year of study of the participants and $\mathrm{Y}$ axis denotes the frequency distribution for the response of the question 'Do you know that survival rate of patients suffering from osteosarcoma has increased on using chemotherapy as an adjuvant for surgery'. Blue colour depicts the participants who are aware of that chemotherapy as an adjuvant for surgery and green colour depicts the participants who are not aware of chemotherapy as an adjuvant for surgery. Awareness was seen more among third years (37.74\%) compared to other years. This was found to be statistically significant. (Chi square test, $\mathrm{P}=\mathbf{0 . 0 1 1}$ ).

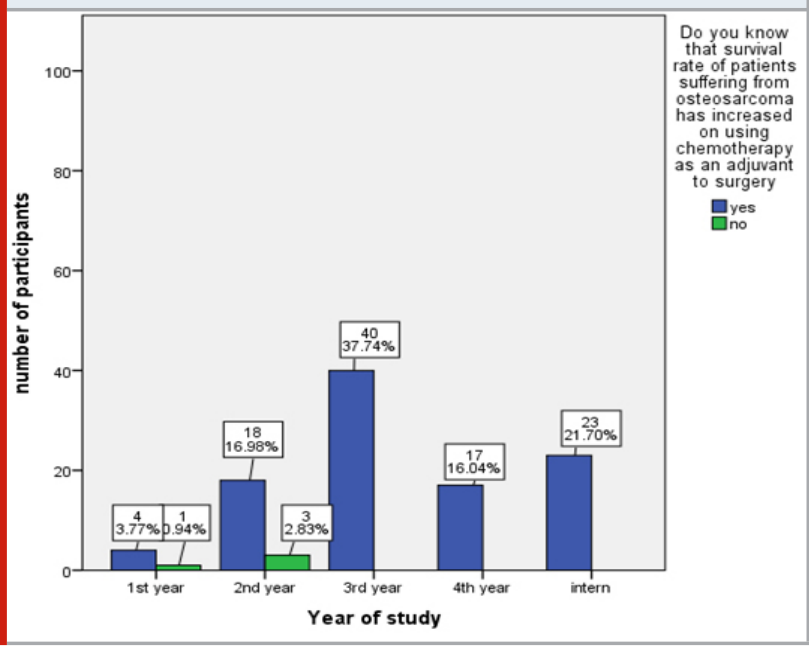

Figure 18: Bar graph depicts the comparison of year of study of participants and awareness of ways to manage osteosarcoma of jaws. $\mathrm{X}$ axis denotes the year of study of the participants and $\mathrm{Y}$ axis denotes the frequency distribution for the response of the question 'Are you aware of ways to manage osteosarcoma of jaws'. Blue colour depicts the participants who are aware of ways to manage osteosarcoma of jaws and green colour depicts the participants who are not aware of ways to manage osteosarcoma of jaws. Awareness was seen more among third years (35.85\%) compared to other years. This was found to be statistically significant. (Chi square test, $\mathrm{P}=0.001$ ).

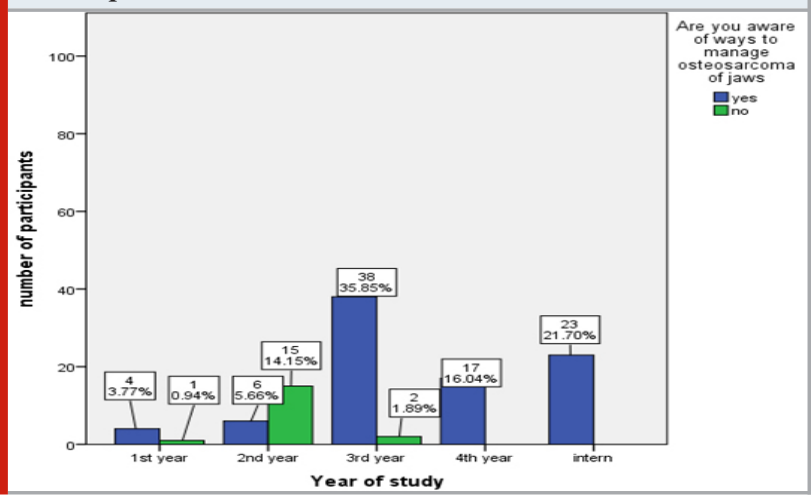

32

\section{CONCLUSION}

This survey aims in creating awareness among dental students about the primary malignant tumour of bone osteosarcoma. It also creates awareness about management of osteosarcoma of jaws. From the results of the survey it is clear that most of the dental students were well aware of osteosarcoma of jaws and also had proper knowledge about the ways to diagnose and manage osteosarcoma.

\section{ACKNOWLEDGEMENTS}

The author would like to thank the study participants for their participation and kind cooperation throughout the study.

Conflict of Interest: The authors declare that there were no conflicts of interest in the present study.

\section{REFERENCES}

Amaral MB, Buchholz Í, Freire-Maia B, et al. (2008) Advanced osteosarcoma of the maxilla: a case report. Medicina oral, patologia oral y cirugia bucal 13(8). academia.edu: E492-5.

Anbu RT, Suresh V, Gounder R, et al. (2019) Comparison of the Efficacy of Three Different Bone Regeneration Materials: An Animal Study. European journal of dentistry 13(1): 22-28.

Ariga P, Nallaswamy D, Jain AR, et al. (2018) Determination of Correlation of Width of Maxillary Anterior Teeth using Extraoral and Intraoral Factors in Indian Population: A Systematic Review. World Journal of Dentistry 9(1): 68-75.

Ashok V and Ganapathy D (2019) A geometrical method to classify face forms. Journal of oral biology and craniofacial research 9(3): 232-235.

August M, Magennis P and Dewitt D (1997) Osteogenic sarcoma of the jaws: factors influencing prognosis. International journal of oral and maxillofacial surgery 26(3). Elsevier: 198-204.

Baghaie F and Motahari P (2003) Osteosarcoma of the jaws: A retrospective study. ACTA MEDICA IRANICA. Available at: https://www.sid.ir/en/journal/ViewPaper. aspx?ID=4703.

Baumhoer D, Brunner P, Eppenberger-Castori S, et al. (2014) Osteosarcomas of the jaws differ from their peripheral counterparts and require a distinct treatment approach. Experiences from the DOESAK Registry. Oral oncology 50(2). Elsevier: 147-153.

Bras JM, Donner R, van der Kwast WAM, et al. (1980) Juxtacortical osteogenic sarcoma of the jaws: Review of the literature and report of a case. Oral surgery, oral medicine, and oral pathology 50(6). Elsevier: 535-544.

Campanacci M (1999) Metastatic Bone Disease. In: Campanacci M (ed.) Bone and Soft Tissue Tumors: 
Clinical Features, Imaging, Pathology and Treatment. Vienna: Springer Vienna, pp. 755-787.

Daffner RH, Fox KR and Galey K (2002) Fibroblastic osteosarcoma of the mandible. Skeletal radiology 31(2). Springer: 107-111.

Donaldson ME, Geist JR and Daley TD (2004) Osteosarcoma of the jaws in children. International journal of paediatric dentistry / the British Paedodontic Society [and] the International Association of Dentistry for Children 14(1). Wiley Online Library: 54-60.

Duraisamy R, Krishnan CS, Ramasubramanian H, et al. (2019) Compatibility of Nonoriginal Abutments With Implants: Evaluation of Microgap at the ImplantAbutment Interface, With Original and Nonoriginal Abutments. Implant dentistry 28(3): 289-295.

Friend SH, Bernards R, Rogelj S, et al. (1986) A human DNA segment with properties of the gene that predisposes to retinoblastoma and osteosarcoma. Nature 323(6089). Springer: 643-646.

Ganapathy DM, Kannan A and Venugopalan S (2017) Effect of Coated Surfaces influencing Screw Loosening in Implants: A Systematic Review and Meta-analysis. World Journal of Dentistry 8(6): 496-502.

Givol N, Buchner A, Taicher S, et al. (1998) Radiological features of osteogenic sarcoma of the jaws. A comparative study of different radiographic modalities. Dentomaxillofacial Radiology 27(6). The British Institute of Radiology: 313-320.

Guadagnolo BA, Zagars GK, Raymond AK, et al. (2009) Osteosarcoma of the jaw/craniofacial region: Outcomes after multimodality treatment. Cancer 115(14). Wiley Online Library: 3262-3270.

Gupta P, Ariga P and Deogade SC (2018) Effect of Monopoly-coating Agent on the Surface Roughness of a Tissue Conditioner Subjected to Cleansing and Disinfection: A Contact Profilometric Study. Contemporary clinical dentistry 9(Suppl 1): S122S126.

Iavarone A and Matthay KK (1992) Germ-line and somatic p53 gene mutations in multifocal osteogenic sarcoma. Proceedings of the. National Acad Sciences. Available at: https://www.pnas.org/content/89/9/4207. short.

Jain AR (2017a) Clinical and Functional Outcomes of Implant Prostheses in Fibula Free Flaps. World Journal of Dentistry 8(3): 171-176.

Jain AR (2017b) Prevalence of Partial Edentulousness and Treatment needs in Rural Population of South India. World Journal of Dentistry 8(3): 213-217.

Jasnau S, Meyer U, Potratz J, et al. (2008) Craniofacial osteosarcoma: Experience of the cooperative GermanAustrian-Swiss osteosarcoma study group. Oral oncology 44(3). Elsevier: 286-294.

Khorate MM, Goel S, Singh MP, et al. (2010) Osteosarcoma of mandible: a case report and review of literature. Journal of cancer science \& therapy 2(4). pdfs.semanticscholar.org: 122-125.

Mark RJ, Sercarz JA, Tran L, et al. (1991) Osteogenic Sarcoma of the Head and Neck: The UCLA Experience. Archives of otolaryngology--head \& neck surgery 117(7). American Medical Association: 761-766.

Marx RE and Stern D (2012) Oral and Maxillofacial Pathology: A Rationale for Diagnosis and Treatment. Hanover Park, IL: Quintessence Pub. Co.,.

Nissanka EH, Amaratunge E and Tilakaratne WM (2007) Clinicopathological analysis of osteosarcoma of jaw bones. Oral diseases 13(1). Wiley Online Library: 82-87.

Ranganathan H, Ganapathy DM and Jain AR (2017) Cervical and Incisal Marginal Discrepancy in Ceramic Laminate Veneering Materials: A SEM Analysis. Contemporary clinical dentistry 8(2): 272-278.

Vadillo RM, Contreras SJS and Canales JOG (2011) Prognostic factors in patients with jaw sarcomas. Brazilian oral research 25(5). Sociedade Brasileira de Pesquisa Odontológica: 421-426.

Varghese SS, Ramesh A and Veeraiyan DN (2019) Blended Module-Based Teaching in Biostatistics and Research Methodology: A Retrospective Study with Postgraduate Dental Students. Journal of dental education 83(4): 445-450.

World Journal of Dentistry (2017) Evaluation of Corrosive Behavior of Four Nickel-chromium Alloys in Artificial Saliva by Cyclic Polarization Test:An in vitro Study. 8(6): 477-482.

Yamamoto Y, Yamamoto N, Tajima K, et al. (2011) Characterization of human multicentric osteosarcoma using newly established cells derived from multicentric osteosarcoma. Journal of cancer research and clinical oncology 137(3). Springer: 423-433. 